\title{
CDC Grand Rounds: Family History and Genomics as Tools for Cancer Prevention and Control
}

\author{
Juan L. Rodriguez, MPH, MS¹; Cheryll C. Thomas, $\mathrm{MSPH}^{1}$; Greta M. Massetti, $\mathrm{PhD}^{1}$; Debra Duquette, $\mathrm{MS}^{2}$; Lindsay Avner ${ }^{3}$;
} John Iskander, MD ${ }^{4}$; Muin J. Khoury MD, PhD ${ }^{5}$; Lisa C. Richardson, MD ${ }^{1}$

Although many efforts in cancer prevention and control have routinely focused on behavioral risk factors, such as tobacco use, or on the early detection of cancer, such as colorectal cancer screening, advances in genetic testing have created new opportunities for cancer prevention through evaluation of family history and identification of cancer-causing inherited mutations. Through the collection and evaluation of a family cancer history by a trained health care provider, patients and families at increased risk for a hereditary cancer syndrome can be identified, referred for genetic counseling and testing, and make informed decisions about options for cancer risk reduction (1). Although hereditary cancers make up a small proportion of all cancers, the number of affected persons can be large, and the level of risk among affected persons is high. Two hereditary cancer syndromes for which public health professionals have worked to reduce the burden of morbidity and mortality are hereditary breast and ovarian cancer syndrome (HBOC) and Lynch syndrome.

Hereditary breast and ovarian cancer syndrome. HBOC most commonly involves pathogenic mutations in two breast cancer susceptibility genes: BRCA1 and BRCA2. Mutations in these genes are associated with increased risk for breast, ovarian, prostate, and pancreatic cancers (2). Approximately one in every 500 women in the United States is estimated to carry a BRCA1 or BRCA2 mutation (2). Each year, BRCA1 and $B R C A 2$ mutations account for $3 \%$ of all breast cancers and $10 \%$ of all ovarian cancers (3). Mutation carriers face a substantially higher risk for developing breast and ovarian cancers by age 70 years than do women in the general population (Table 1) $(4,5)$. Persons are more likely to have a BRCA1 or BRCA2 mutation if they or their close relatives on either their mother's or father's side of the family have had breast cancer before age 50 years, triple negative breast cancer,*

\footnotetext{
*Triple negative breast cancer is a sub-type of breast cancer diagnosed based upon the absence of three receptors associated with most breast cancers, estrogen receptors, progesterone receptors, and human epidermal growth factor receptor 2 (commonly referred to as HER-2).
}

This is another in a series of occasional MMWR reports titled $C D C$ Grand Rounds. These reports are based on grand rounds presentations at CDC on high-profile issues in public health science, practice, and policy. Information about CDC Grand Rounds is available at http:// www.cdc.gov/aboutlgrand-rounds. ovarian cancer, cancer in both breasts, breast cancer in a male relative, or multiple relatives with breast, pancreatic, or high grade prostate cancer (2). In addition, persons of Ashkenazi Jewish or Eastern European descent are much more likely to have a mutation (approximately 1 in 40) (2). The United States Preventive Services Task Force (USPSTF) recommends that primary care providers screen women to identify a family history that might be indicative of HBOC (1). Women with a family history consistent with HBOC should be referred for genetic counseling and discussion of genetic testing (1). Patients and providers can then jointly determine the best course of action to reduce risk. Possible interventions include starting breast cancer screening earlier with mammography alone, or in combination with breast magnetic resonance imaging, chemo-prevention medications as recommended by the USPSTF, such as tamoxifen or raloxifene, or surgical options, such as risk-reducing mastectomy or oophorectomy $(1,6)$.

Lynch syndrome. Lynch syndrome involves pathogenic mutations in DNA mismatch repair genes (7). Mutations in these genes are associated with increased risk for certain cancers, including colorectal cancer, and cancers of the endometrium and ovary (7). Each year, Lynch syndrome accounts for 1\%-3\% of all colorectal cancer cases (8). The risk for colorectal cancer among persons with Lynch syndrome is substantially higher than that of the general population (Table 1) (9). Persons are more likely to have Lynch syndrome if they or their close relatives have had colorectal, endometrial, or ovarian cancers, especially at younger ages (7). The Evaluation of Genomic Applications in Practice and Prevention (EGAPP) Working Group $^{\dagger}$ recommends that persons with newly diagnosed colorectal cancer be offered genetic testing for Lynch syndrome to reduce morbidity and mortality in their close relatives (10). Persons with Lynch syndrome can talk to their health care provider about starting screening for colorectal cancer with colonoscopy at a younger age and screening more frequently than persons who are at average risk (10).

\footnotetext{
The EGAPP Working Group was established in 2005 to support the development of a systematic process for assessing the available evidence regarding the validity and utility of rapidly emerging genetic tests for clinical practice. This independent, multidisciplinary panel prioritizes and selects tests, reviews CDC-commissioned evidence reports and other contextual factors, highlights critical knowledge gaps, and provides guidance on appropriate use of genetic tests in specific clinical scenarios (http://www.egappreviews.org/).
} 
TABLE 1. Estimated number of cancers diagnosed among the general population and among women with a $B R C A$ mutation (breast and ovarian cancers) and among persons with Lynch syndrome (colorectal cancer)

\begin{tabular}{lcc}
\hline Type of Cancer & $\begin{array}{c}\text { Women in general } \\
\text { population }\end{array}$ & $\begin{array}{c}\text { Women with } B R C A \\
\text { mutation* }^{*}\end{array}$ \\
\hline Breast cancer & $12 / 100$ & $65 / 100$ \\
Ovarian cancer & $1 / 100$ & $39 / 100$ \\
\hline & $\begin{array}{c}\text { Persons in general } \\
\text { population }\end{array}$ & $\begin{array}{c}\text { Persons with Lynch } \\
\text { syndrome }^{\dagger}\end{array}$ \\
Colorectal cancer & $4 / 100$ & $40 / 100$ \\
\hline
\end{tabular}

* Antoniou A, et al. J Hum Genet 2003;72:1117-30.

† Palomaki GE, et al. Genet Med 2009;11:42-65.

Public health for cancer genomics at the federal level. CDC's work is focused on translating and implementing recommendations for family history risk assessment, and genetic counseling and testing for hereditary cancer syndromes. CDC activities include surveillance, epidemiology and research, communication, and partnerships. Knowledge and resources for patients and providers are shared through the Know:BRCA clinical decision support tool (www.KnowBRCA.org), and Bring Your Brave campaign (http://www.cdc.gov/cancer/ breast/young_women/bringyourbrave/). Know:BRCA helps women and their providers understand their risk for $B R C A 1$ or $B R C A 2$ mutations and fosters discussions about family history. Bring Your Brave is a digital media campaign that provides information about $\mathrm{HBOC}$, the importance of receiving genetic counseling, and the usefulness of genetic testing to women, particularly women aged $\leq 45$ years. The CDC Public Health Cancer Genomics Program funds cooperative agreements to five state public health departments to build capacity for cancer genomics activities (11). CDC's grantees implement activities that seek to educate the public and providers, monitor the burden associated with hereditary cancers, and improve access to care. ${ }^{\S}$

Public health initiatives for cancer genomics at the state level. The Michigan Cancer Genomics Program of the Michigan Department of Health and Human Services has been engaging in cancer genomics activities since 2003. The Michigan Cancer Genomics Program seeks to reduce morbidity and mortality related to hereditary cancers by increasing cancer genetic literacy among the public and health care providers, improving use of appropriate cancer risk assessment and clinical genetics services, enhancing communication, and developing partnerships with cancer genetic service providers and other key stakeholders.

After identifying a need for further awareness and training among primary care providers about appropriate referral for $B R C A$ counseling and testing, the Michigan Cancer Genomics

\footnotetext{
$\$$ CDC Public Health Cancer Genomics Program (http://www.cdc.gov/cancer/ breast/what_cdc_is_doing/genomics_foa.htm).
}

Program collaborated with federal, state, and local partners to develop a free online continuing medical education course wherein participants can learn to use a variety of cases with different decision options, risks, and outcomes (http://www. nchpeg.org/hboc/). The course has had approximately 4,400 session views since its launch in 2014. An additional initiative, a collaboration with the Michigan Cancer Surveillance Program, disseminated reports to health care systems and providers with information about how and where to refer patients for cancer genetics services.

In part because of the efforts of the Michigan Cancer Genomics Program, the number of persons receiving $B R C A$ counseling and testing in Michigan has been increasing since 2008 (Figure). The Michigan Cancer Genomics Program has also been successful in working with health insurance providers in promoting coverage policies that are consistent with evidence-based guidelines to ensure access to genetic counseling and testing for Michigan residents. In 2009, only four of 25 health plans in the state were acknowledged for having written coverage policies consistent with evidence-based guidelines. In 2016, 16 health plans, providing coverage to approximately 8 million persons in Michigan, now provide coverage based on the best scientific evidence. The Michigan Cancer Genomics Program is currently working on addressing disparities in access to genetic counseling and testing by conducting outreach to communities and populations with the greatest need, including African Americans and Ashkenazi Jews.

Public health initiatives for cancer genomics at the community level. Bright Pink is a national nonprofit organization founded by Lindsay Avner, a woman with a family history of breast and ovarian cancer and a BRCA1 mutation (https:// www.brightpink.org/). The organization focuses on prevention and early detection of breast and ovarian cancer in young

FIGURE. BRCA counseling, testing, and results - Michigan Cancer Genomics Program, 2008-2013

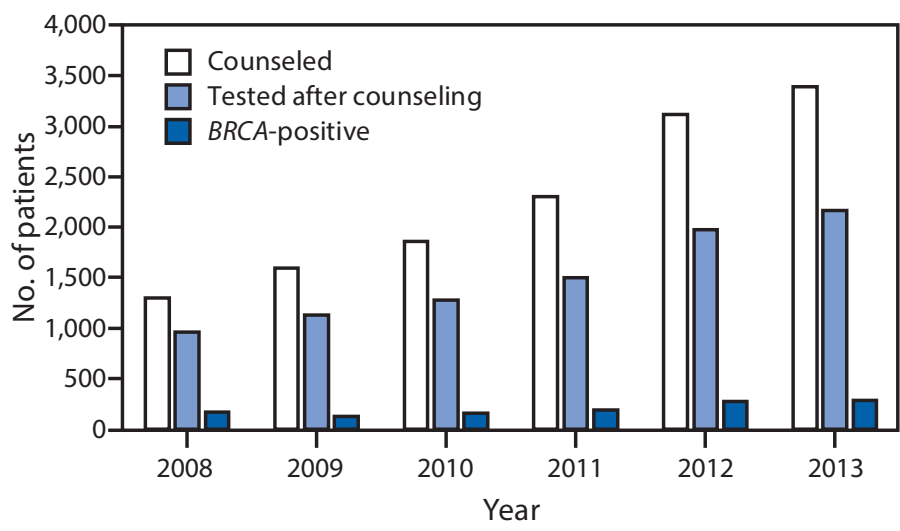

Source: Michigan Department of Health and Human Services BRCA Clinical Genetic Counseling Database. 
women using a two-pronged educational approach that targets young women and health care providers. Bright Pink has 150 ambassadors in 39 states who train young women in their communities and workplaces using the Brighten Up Educational Workshop; the workshop provides a brief overview of breast and ovarian health basics, including signs and symptoms, early detection practices, risk reduction, family history, and risk assessment. For women who are considered to be at high risk, Bright Pink offers one-on-one outreach and digital support programs to foster community among women challenged with complex health decisions that peers who are at average risk might not understand. For health care providers, Bright Pink offers a didactic format lecture and accompanying case-based learning module that emphasize proper risk stratification and management for women at all risk levels, an understanding of risk as a spectrum, and the importance of women knowing how their breasts normally look and feel to recognize any changes. USPSTF recommendations for genetic counseling testing and risk reduction strategies are also discussed with health care providers and women at increased risk. As of August 2016, Bright Pink has trained nearly 50 speakers with a medical background who have reached approximately 8,000 providers at more than 150 institutions, ranging from community health settings to academic medical centers.

The future of public health genomics. Cancer serves as a model for public health action in genomics that can aid in translating future genomic discoveries into prevention and population health activities. Public health can play an important role in these activities by identifying genomic tests and family health history applications that are supported by high quality evidence, by estimating the potential population health impact of including genomics and family health history, and by integrating appropriate and equitable use of genomics applications in clinical care and public health programs.

To assist public health professionals in identifying which genomic tests and family health history applications can impact population health, CDC developed a classification schema for genomic tests based on levels of evidence, ranked Tier 1-3 (Table 2) (12). Tier 1 applications are supported by a base of synthesized evidence for implementation in practice and cover a variety of intended uses including diagnosis, prognosis, treatment, screening, and risk prediction to inform prevention. Genetic testing for BRCA-related cancers and Lynch syndrome are only two of approximately 30 Tier 1 applications related to cancer. In addition, family health history is a genomics application included in many evidence-based recommendations and can be applied more broadly in public health settings (13). CDC launched a Tier 1 toolkit to assist state health
TABLE 2. CDC Classification schema for genomic tests based on level of evidence

\begin{tabular}{|c|c|c|}
\hline Tier & Evidence for recommendation & Examples \\
\hline Tier 1 & $\begin{array}{l}\text { Supported by a base of synthesized } \\
\text { evidence for implementation practice }\end{array}$ & $\begin{array}{l}\text { HBOC, Lynch } \\
\text { syndrome, newborn } \\
\text { screening }\end{array}$ \\
\hline Tier 2 & $\begin{array}{l}\text { Synthesized evidence is insufficient to } \\
\text { support routine implementation in } \\
\text { practice; may provide information for } \\
\text { informed decision making }\end{array}$ & $\begin{array}{l}\text { Many } \\
\text { pharmacogenomics } \\
\text { tests }\end{array}$ \\
\hline Tier 3 & $\begin{array}{l}\text { Evidence-based recommendation against } \\
\text { use; or not relevant synthesized evidence } \\
\text { identified; not ready for routine } \\
\text { implementation in practice }\end{array}$ & $\begin{array}{l}\text { Direct-to-consumer } \\
\text { personal genetic tests }\end{array}$ \\
\hline
\end{tabular}

Abbreviation: $\mathrm{HBOC}=$ Hereditary breast and ovarian cancer syndrome.

departments in implementing genomics activities related to HBOC and Lynch syndrome, with examples of approaches and materials used by model state programs. 9

Some have raised concerns that genomic technologies and precision medicine initiatives could increase health disparities (14). For example, studies have found lower use of genetic counseling and testing for $B R C A$ mutations among black women (15). To ensure that implementation of genomics applications results in health benefits for all, a public health approach is needed that promotes strategies for equitable access and protection for persons identified as being at higher-than-average risk; addresses education of providers and the public to increase appropriate use; and supports surveillance to monitor and evaluate use (14). Recent national policies and legislation have been enacted that support broader use of genomics and offer protections for persons identified to be at increased risk. The Genetic Information Nondiscrimination Act (2008) prohibits discrimination in health coverage and employment based on genetic information. Programs such as the Surgeon General's Family Health History Initiative (http://familyhistory.hhs.gov/) help educate both providers and the public about the importance of family health history. Surveillance of outcomes and use of genomic applications is important for identifying whether current applications have health benefits and whether there is equitable access. Future development of policies, education, and surveillance systems can work to further the implementation of genomic applications that might provide broad benefits.

The Tier 1 Genomics Applications Toolkit for Public Health Departments
(https://www.cdc.gov/genomics/implementation/toolkit/tier1.htm).

${ }^{1}$ Division of Cancer Prevention and Control, CDC; ${ }^{2}$ Michigan Department of Health and Human Services; ${ }^{3}$ Bright Pink, Chicago, Illinois; ${ }^{4}$ Office of the Associate Director for Science, CDC, ${ }^{5}$ Office of Public Health Genomics, CDC. Corresponding author: Juan L. Rodriguez, JRodriguez2@cdc.gov, 770-488-3086. 


\section{References}

1. Moyer VA; US Preventive Services Task Force. Risk assessment, genetic counseling, and genetic testing for BRCA-related cancer in women: US Preventive Services Task Force recommendation statement. Ann Intern Med 2014;160:271-81.

2. Petrucelli N, Daly MB, Feldman GL. BRCA1 and BRCA2 hereditary breast and ovarian cancer. In: Pagon RA, Adam MP, Ardinger HH, et al., eds. GeneReviews [Internet]. Seattle, WA: University of Washington, Seattle; 2013. http://www.ncbi.nlm.nih.gov/books/NBK1247/

3. Nelson HD, Fu R, Goddard K, et al. Risk assessment, genetic counseling, and genetic testing for $B R C A$-related cancer: systematic review to update the U.S. Preventive Services Task Force recommendation evidence synthesis no. 101. Agency for Healthcare Research and Quality publication no. 12-05164-EF-1. Rockville, MD: Agency for Healthcare Research and Quality; 2013.

4. Antoniou A, Pharoah PD, Narod S, et al. Average risks of breast and ovarian cancer associated with BRCA1 or BRCA2 mutations detected in case series unselected for family history: a combined analysis of 22 studies. Am J Hum Genet 2003;72:1117-30. http://dx.doi.org/10.1086/375033

5. Chen S, Parmigiani G. Meta-analysis of BRCA1 and BRCA2 penetrance. J Clin Oncol 2007;25:1329-33. http://dx.doi.org/10.1200/ JCO.2006.09.1066

6. Moyer VA; US Preventive Services Task Force. Medications for risk reduction of primary breast cancer in women: US Preventive Services Task Force recommendation statement. Ann Intern Med 2013;159:698-708.

7. Kohlmann W, Gruber SB. Lynch syndrome. In: Pagon RA, Adam MP, Ardinger HH, et al., eds. GeneReviews [Internet]. Seattle WA: University of Washington, Seattle; 2014. http://www.ncbi.nlm.nih.gov/books/ NBK1211/
8. Kaz AM, Brentnall TA. Genetic testing for colon cancer. Nat Clin Pract Gastroenterol Hepatol 2006;3:670-9. http://dx.doi.org/10.1038/ ncpgasthep0663

9. Palomaki GE, McClain MR, Melillo S, Hampel HL, Thibodeau SN. EGAPP supplementary evidence review: DNA testing strategies aimed at reducing morbidity and mortality from Lynch syndrome. Genet Med 2009;11:42-65. http://dx.doi.org/10.1097/GIM.0b013e31818fa2db

10. Evaluation of Genomic Applications in Practice and Prevention (EGAPP) Working Group. Recommendations from the EGAPP Working Group: genetic testing strategies in newly diagnosed individuals with colorectal cancer aimed at reducing morbidity and mortality from Lynch syndrome in relatives. Genet Med 2009;11:35-41. http://dx.doi.org/10.1097/GIM.0b013e31818fa2ff

11. Trivers KF, Rodriguez JL, Cox SL, Crane BE, Duquette D. The activities and impact of state programs to address hereditary breast and ovarian cancer, 2011-2014. Healthcare 2015;3:948-63. http://dx.doi. org/10.3390/healthcare3040948

12. Dotson WD, Douglas MP, Kolor K, et al. Prioritizing genomic applications for action by level of evidence: a horizon-scanning method. Clin Pharmacol Ther 2014;95:394-402. http://dx.doi.org/10.1038/clpt.2013.226

13. Khoury MJ, Bowen MS, Burke W, et al. Current priorities for public health practice in addressing the role of human genomics in improving population health. Am J Prev Med 2011;40:486-93. http://dx.doi. org/10.1016/j.amepre.2010.12.009

14. Khoury MJ, Galea S. Will precision medicine improve population health? JAMA 2016;316:1357-8. http://dx.doi.org/10.1001/jama.2016.12260

15. McCarthy AM, Bristol M, Domchek SM, et al. Health care segregation, physician recommendation, and racial disparities in BRCA1/2 testing among women with breast cancer. J Clin Oncol 2016;34:2610-8. http:// dx.doi.org/10.1200/JCO.2015.66.0019 